\title{
Optimization Reservoir Operation for Irrigation Using Fuzzy Logic of Jayakwadi Dam
}

\author{
Sahil Sanjeev Salvi \\ M. Tech., Environmental \& Water Resources Engineering, College Of Engineering Pune, Maharashtra, India
}

\begin{abstract}
Reservoir operation is an important aspect in water resources planning and management. It consists of several control variables that defines the operation strategies for guiding a sequence of release to satisfy demands with various objectives, such as flood control, hydropower generation, irrigation and drinking purposes. A major difficulty in the operation of reservoirs is the often conflicting and unequal objectives. Therefore, it is necessary to optimize reservoir operation in determining balanced solutions between the conflicting objectives. In this study, optimization reservoir operation was carried out of Jayakwadi dam using fuzzy logic for irrigation purpose. The study reveals that fuzzy logic model based on MATLAB is very useful for irrigation water release corresponding to the maximum level of satisfaction and more comfortable for operators.
\end{abstract}

Keywords: Fuzzy Inference System, Jayakwadi dam, Matlab 2013, Optimization Reservoir Operation

\section{Introduction}

Water resource engineering is concerned with the utilization of water, control of water and water quality management. Water quality management is also an important phase of water resources engineering to maintain the required quality of water for municipal and irrigation uses and to preserve the environment and ecological balance. Because of the high temporal and geographical variability with respect to rainfall in this country, reservoir operation occupies an important place in the utilization of water resources. The situation of too much water in rainy season and too little water in the dry season causes many difficulties in reservoir operation. It is necessary to emphasize that the reservoir operation policies should be used to global climate change as well as economic activities in the river basin. Due to change of hydrometeorological condition and water requirement from one region to the other, the reservoir has different operation rules. Therefore, without careful consideration of this condition the reservoir operation will be inefficient.

System engineering approach to the water resources system resorts to a schematic analysis of the numerous choices and options to the policy and decision makers. Not only much larger number of alternatives is considered, but each alternative representing a complex problem of inter-related effects must be evaluated in respect of their effects at various locations. Reservoirs are operated according to a set of rules or guidelines for storing and releasing water, depending on the purpose to be served. Regulation plans to cover all the complicated situations may be difficult to evolve, but generally, it may be possible according to the following commonly adopted principles of reservoir operation for flood control and conservational uses in case of single purpose, multipurpose and system of reservoirs. These guidelines are broad generalization only and are indicative in nature. For actual operation of reservoir or a system of reservoirs, individual regulation schedules are required to be formulated after considering all critical factors involved. In

The present study, optimal reservoir operation model is developed using Fuzzy Interference system (FIS) and applied to determine the monthly operating rules for the
Jayakwadi reservoir stage-I, which is constructed on river Godavari.

\section{Study Area}

The Jayakwadi Project Report Stage-I is constructed across river Godavari in Paithan of Aurangabad district, Maharashtra. The catchment area of reservoir up to dam site is $21,750 \mathrm{~km}^{2}$. The gross storage reservoir is $2909 \mathrm{Mm}^{3}$ and live storage is $2171 \mathrm{Mm}^{3}$. Total installed capacity for power generation is $12 \mathrm{MW}$ (pumped storage plant). Irrigable command area is 1, 41,640 ha. Area of irrigation in Kharif is $22 \%$, in Rabi $45 \%$, two seasonal $28 \%$, hot weather $3 \%$ and perennial crops $4.5 \%$. The soils in the command of the Jayakwadi Project area eminently suited to the growth of cotton and Rabi crops which can be irrigated cover and large area with relatively low consumption of water, i.e. low delta.

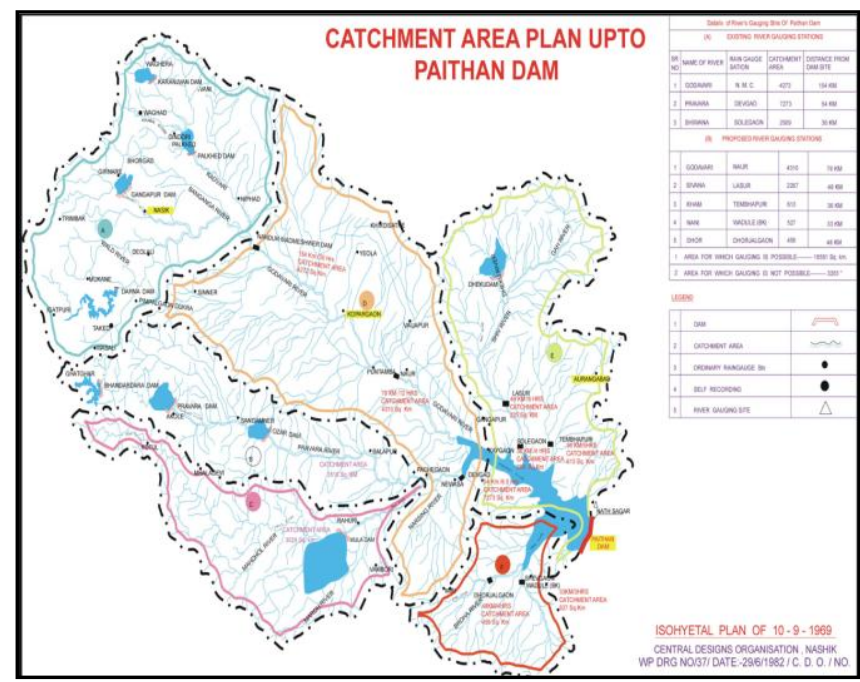

Figure 1: Catchment Area of Jayakwadi Dam

Jayakwadi project is mainly constructed to irrigate land for agriculture of Marathwada region of Maharashtra state. Other important purpose is to provide water for drinking and industrial usage to nearby towns and villages and to the municipalities and industrial area of Aurangabad and Jalna districts. 


\section{International Journal of Science and Research (IJSR) \\ ISSN (Online): 2319-7064}

Index Copernicus Value (2015): 78.96 | Impact Factor (2015): 6.391

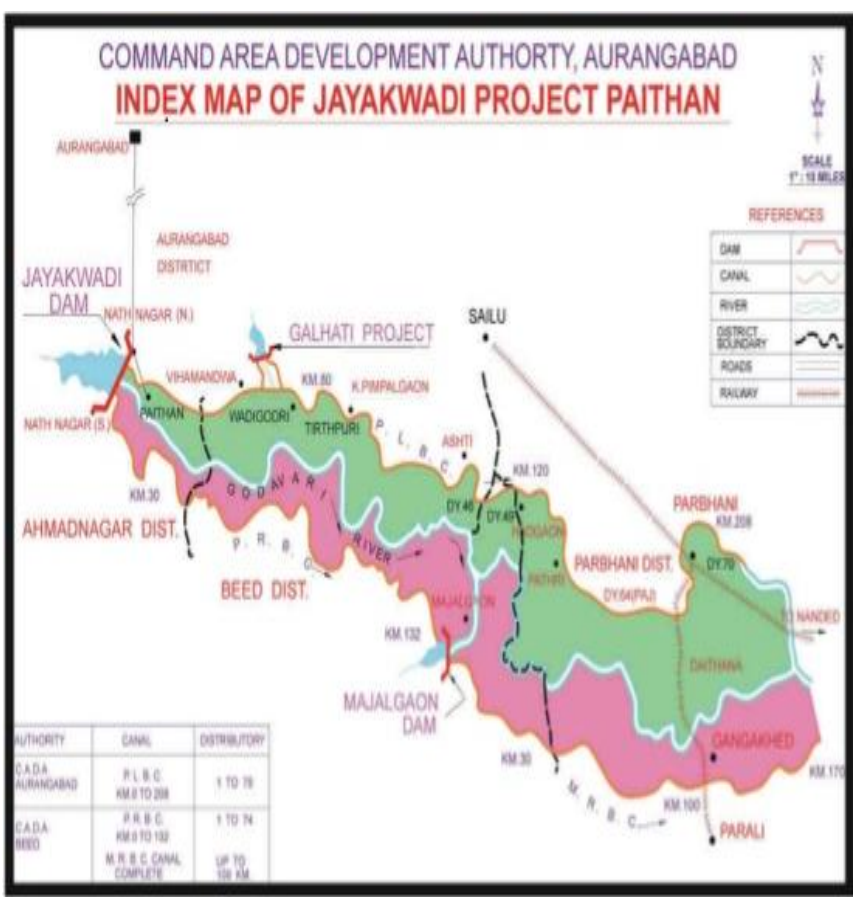

The $80 \%$ of water from dam is used for irrigation, $5-7 \%$ for drinking water and the rest for industrial purposes. The average daily discharge of the dam is around $1.36 \mathrm{Mm}^{3}$, out of which $0.05 \mathrm{Mm}^{3}$ of water is supplied to the MIDC area, $0.15 \mathrm{Mm}^{3}$ is distributed to fulfill the needs of Aurangabad city, while the remaining amount is lost in evaporation.

\section{Aim and Objectives of the study}

The basic aim of this study is to maximize the benefits of water use for irrigation purpose through Jayakwadi Dam while satisfying the constraints of the problem.

The main objective of the study is to carry out the desired optimization of Single purpose reservoir operation using MATLAB. The objective of the present study is to demonstrate the application of some of the system analysis method for optimal operation of water resources system so as to cater to the objective needs. With the change in the policy and the development that is taking place in the agricultural, industrial and domestic sector any water resource system whether already in operation or planning for operation should cater to the need. Therefore, it is necessary to create awareness on the usefulness of the modern method to obtain solution in water resource problem.

\section{Data and Methodology}

Water resources system is very complex in nature because of multiplicity of goals and objectives, the planner has to adopt the best among the various alternatives. With the arrival of digital computers, it has been possible to handle large amount of data efficiently and also to analyze the problems for mathematical solutions speedily. In the present study, following variables with respect to Jayakwadi dam are used as input for model in MATLAB.

- Storage of reservoir (SC)

- Inflow to reservoir (IF)

- Evaporation losses (EL)
- Irrigation Demand (Id)

- Release for water supply (RI)

\begin{tabular}{|c|c|}
\hline \multicolumn{2}{|c|}{ Jayakwadi Dam and Reservoir } \\
\hline Gross Capacity at F.R.L. & $\begin{array}{c}2909 \mathrm{Mm}^{3} \\
(102.72 \mathrm{TMC})\end{array}$ \\
\hline Capacity of Dead Storage & $738 \mathrm{Mm}^{3}(26.62 \mathrm{TMC})$ \\
\hline Capacity of Live Storage & $2170 \mathrm{Mm}^{3}(76.62 \mathrm{TMC})$ \\
\hline Carry over & $13.48(\mathrm{TMC})$ \\
\hline Evaporation Losses & $22.40(\mathrm{TMC})$ \\
\hline Area under submergence at F.R.L. & 86,000 Acres \\
& $(35,000$ ha. $)$ \\
\hline Spillway crest & $455.96 \mathrm{~m}$ \\
\hline F.R.L. & $463.906 \mathrm{~m}$ \\
\hline M.W.L. & $465.582 \mathrm{~m}$ \\
\hline T.D.L. & $468.94 \mathrm{~m}$ \\
\hline Max. Height of dam & $37.73 \mathrm{~m}$ \\
\hline Length of dam & $10280 \mathrm{~m}$ \\
\hline Type of dam & Earthen \\
\hline Villages under submergence & $96+11=107$ (No.) \\
\hline Population of project affected & 76280 \\
\hline \multicolumn{2}{|c}{} \\
\hline
\end{tabular}

Main application of the fuzzy theory in a reservoir operation model is to study the behavior of the regularized flow. The application of fuzzy sets theory can provide a viable way to handle situations when problems with objectives are difficult to define due to imprecision. Fuzzy set theory gives the ability to work with measures of satisfaction by using fuzzy membership functions means The degree of truth attached to that statement is defined by a membership function ranges from 0 (completely false) to 1 (completely true).In the case of reservoir operation, fuzzy membership functions may be described in terms of water level, release, and water quality parameters.

\section{Irrigation demand constraint}

Release into canal for irrigation (RI) should be less than or equal to irrigation demand (ID). Release should also be greater than minimum irrigation required so that the crop will not wilt ( $30 \%$ of the irrigation demand is considered as minimum irrigation demand) for all the time periods.

$$
\mathrm{RI}_{\mathrm{t}} \leq 0.3 \mathrm{IDt}
$$

\section{Reservoir storage capacity constraint}

The live storage in the reservoir should be less than or equal to the maximum capacity (SC) for all the time periods.

$$
\mathrm{S}_{\mathrm{t} \leq \mathrm{SC}}
$$

In modeling of reservoir operation with fuzzy logic, the following distinct steps are followed: 


\section{International Journal of Science and Research (IJSR) \\ ISSN (Online): 2319-7064}

Index Copernicus Value (2015): 78.96 | Impact Factor (2015): 6.391

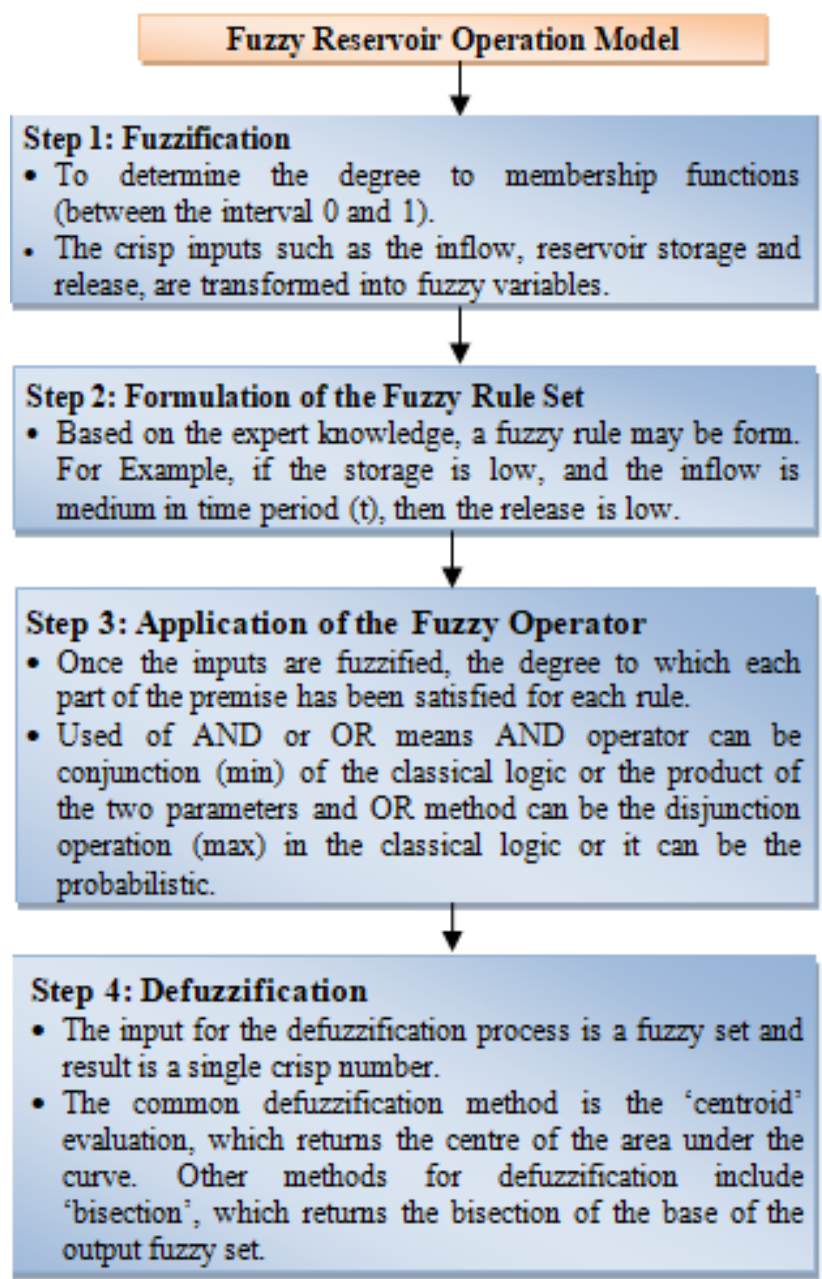

\section{Result and Analysis}

In the present study, FIS model for reservoir operation is developed and demonstrated over an existing system on river Godavari, namely Jayakwadi Project in the state of Maharashtra. The Fuzzy interference system tool box available with the MATLAB software is used for developing the model. The inputs to the fuzzy system are inflows, storage, and time-of-year. The demand is assumed to be uniquely defined for a period, and hence the variable timeof-year (the period number) is taken as the equivalent input. The output is the release during the period. For the inputs and output operations, the logical and implication operators are taken as (with conventional Fuzzy notation),

\begin{tabular}{|ccc|}
\hline And Method & $=$ & 'Min'; \\
\hline Or Method & $=$ & 'Max'; \\
\hline Defuzzification Method & $=$ & 'Centroid'. \\
\hline
\end{tabular}

Where the 'And' and 'Or' method corresponds to the conjunction $(\min )$ and disjunction $(\max )$ operation of classical logic.

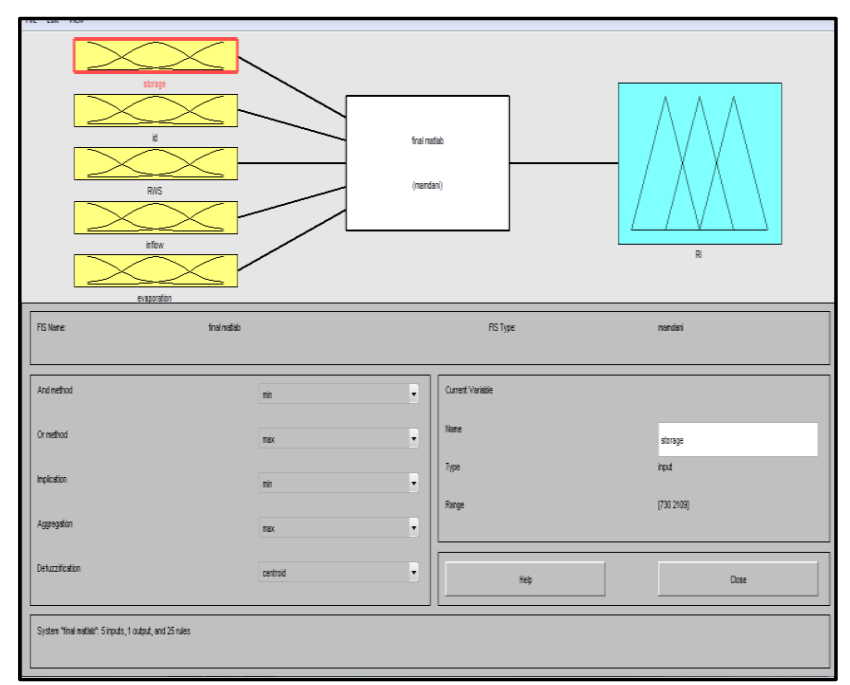

Figure 2: FIS Editor

Input For Data :

Membership function values are traced to 'very low', 'low', 'medium', 'high', 'very high' of storage, inflow (IF), River Water Supply (RWS), Irrigation Demand (ID), Evaporation and release membership functions, respectively.

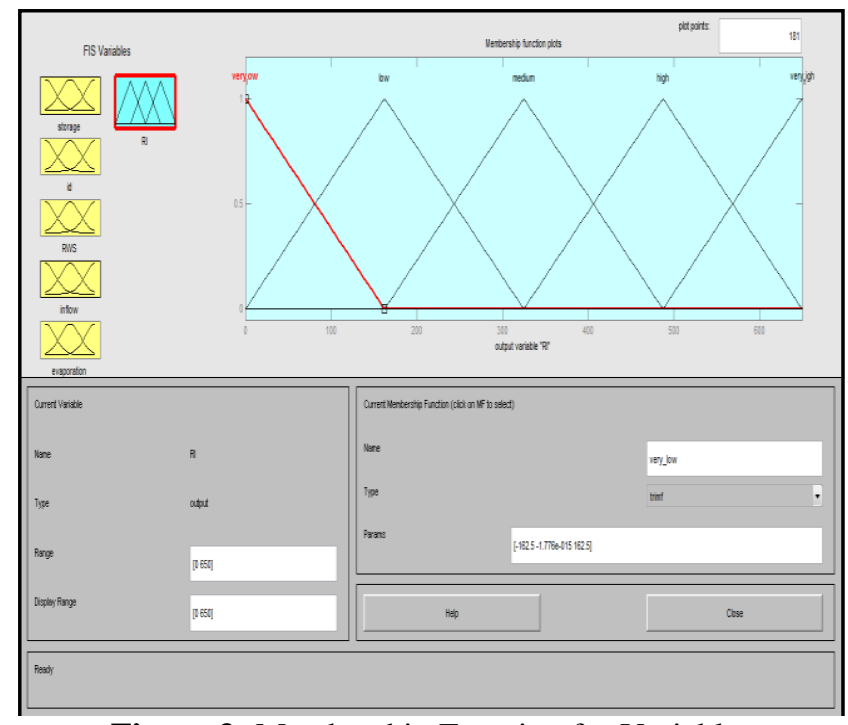

Figure 3: Membership Function for Variables

\section{Output (RI):}

Knowing the reservoir storage and inflow levels (i.e., high, medium etc.), appropriate fuzzy rule for the period is invoked. The fuzzy operator, implication and aggregation together yield a fuzzy set for the release. A crisp release is then obtained by using the centroid of the fuzzy set. 


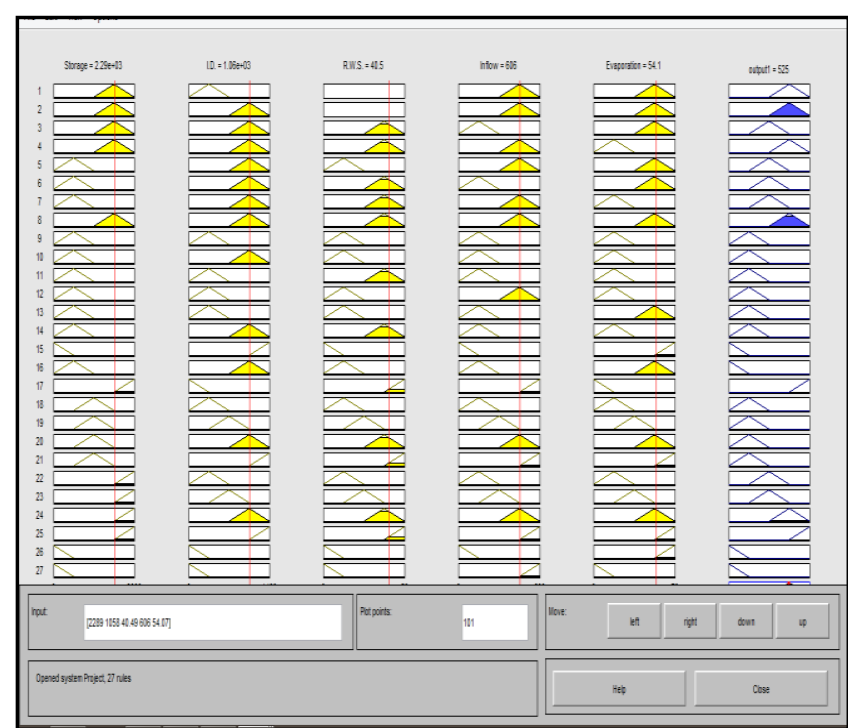

Figure 4: Generated Fuzzy Rules

\section{Conclusion}

The conclusions obtained from the present study of various are summarized as follows:

1) Irrigation release corresponding to the maximum level of satisfaction is $\mathbf{5 9 0 . 4 0} \mathrm{Mm}^{3}$ and sum of release for irrigation after optimization by using F.I.S. is $\mathbf{5 2 5 . 0 0}$ $\mathrm{Mm}^{3}$.

2) A fuzzy rule based model is developed for the operation of single purpose reservoir for the purpose of optimization model for maximization of irrigation.

3) The model operates on 'if-then principle', where the 'if' is a vector of fuzzy premises and the 'then' is a vector of fuzzy consequences.

4) Fuzzy rule based reservoir operation is that complex optimization procedures are avoided, and linguistic statements such as 'low inflow' 'poor rainfall' etc., may be readily incorporated. As a result, the operators may feel more comfortable in using such models.

\section{References}

[1] Azhar Husain, "An overview of reservoir systems operation techniques", International Journal of Engineering Research and Development, 4(10), pp.3037.

[2] Dattatray G. Regulwar, Ravindra U. Kamodkar, "Derivation of Multipurpose Single Reservoir Release Policies with Fuzzy Constraints", Journal of Water Resource and Protection, 2, pp.1030-1041, 2010.

[3] D.P.Panigrahi and P.P.Mujumdar, "Reservoir operation modeling with Fuzzy Logic", Journal of Water Resources Management, 14, pp.89-109, 2000.

[4] Mujumdar, P.P and Ramesh, T.S.V., "Real-time reservoir operation for irrigation", Journal of Water Resources Research, 33(5), 1997, pp.1157-1164.

[5] Nagesh Kumar, D.,Prasad, D.S.V., Srinivasraju, K., "Optimal Reservoir Operation Using Fuzzy Approach ", Indian Institute of technology, Kharagpur, India, pp.1-8.

[6] R.U.Kamodkar, D.G.Regulwar, "Multipurpose Reservoir operating policies: A Fully Fuzzy Linear Programming Approach", Journal of Agricultural Science and Technology, 15, pp.1261-1274, 2013.
[7] Regulwar, D.G., and Anand Raj, "Optimal Operation of Multiple Reservoir Systems - A Case Study", Proceedings of International conference on Hydrological Perspective for Sustainable Development, IIT Roorkee, pp.620-630, 2005.

[8] Zadeh, L.A., "Fuzzy Set". Information and control, 8, pp.338-353, 1965.

[9] Zimmermann, H.J.: Fuzzy mathematical programming, Compute and Ops. Res. 10(4), pp.291-298, 1983. 